\title{
Impact of Conditional Factors on Internal Control System in Keeping with the Requirements of Information Technology from the Point of View of IT Auditors at Commercial Banks in Jordan
}

\author{
Atallah Ahmad Swielem Al-Hosban ${ }^{1}$ \\ ${ }^{1}$ Irbid National University, Jordan \\ Correspondence: Atallah Ahmad Swielem Al-Hosban, Irbid National University, Irbid, Jordan. Tel: \\ 9627-7543-7120. E-mail: aalhosban@gmail.com \\ Received: August 22, 2014 \\ Accepted: September 9, 2014 \\ Online Published: October 25, 2014 \\ doi:10.5539/ijef.v6n11p245 \\ URL: http://dx.doi.org/10.5539/ijef.v6n11p245
}

\begin{abstract}
This study aims to Identify the linking of police supervision of the internal control system and identify the impact of these link in promoting the concept of banking supervision, and highlight the concept of conditional and control areas of evolution and their use. This study depends up on deductive approach: through the questionnaire user-friendly design and characteristics of the study include the study variables and assumptions. the most finding of this study: An Auditors provide management about the reliability of it systems and how to control environmental factors both internal factors or external factors and internal oversight helps to identify opportunities and threats of the external environment and identify the strengths and weaknesses of the internal environment factors. An Auditor shall determine the conditions of uncertainty in the information technology environment which reduces risks of modern technology and investment opportunities by internal oversight, and auditors should focus on expanding the information and try to adjust its deployment in large organizations because it will have a wide range of information about internal activities. Main recommendation are: the auditor training and education programmers on information security risks and their impact on the company's working environment. The role of internal audit and the internal control system in determining a company's information technology tools, audit, and determine the costs for those programs, and conferences, seminars, known researcher conditional control factors on large business organizations particularly banks.
\end{abstract}

Keywords: conditional factors, IT auditor, information technology, commercial banks, internal control system

\section{Introduction}

Condition management has three phases, collecting information, which is comparable to traditional condition monitoring, analyzing information to spot trends and areas requiring action, and acting on the results. Also, where traditional condition monitoring tends to be equipment or area focused, condition management takes a complete contextual view, in bringing together operations, maintenance and engineering to resolve critical business issues, condition management's ability to collect key performance data to support RCM (Reliability Centered Maintenance) analysis.

Design of any system of planning or control is selected officers (circumstantial), where there are a number of possibilities that must be taken into account in a specific position, this means the conditional application of many activities and tools involved in designing, planning and control systems, so the conditional framework prevailing in research design, and this in turn means that there are variables that control systems are the systems of support and promotion, and use all the control mechanisms in the organization or a court (Fisher, 1995, p. 24).

The conditional entry or conditional based on theory in the design of accounting and control systems, which builds on the basis that there is no general accounting system for both organizations and for all circumstances, but whenever the special circumstances of the organization, oversight systems must adapt and change if the organization is to remain active. The appropriateness of the various control systems depends on the status of work and positions, and the rapidly changing conditions imposed on users of information systems challenges, so the need is urgent and necessary to the existence of conditional factors having an impact on the design of control systems and the adaptation of those factors with the internal control system and rapid changes on corporate business (Odeh, 1999, p. 63). 
And the same result obtained by Charles Grand that in technological developments, no accounting system or control system suitable for all times and places, but change the requirements and conditions of control systems by news events affecting the company's business, and that the control systems must adapt and be flexible to deal with the changes in information technology. So the focus will be on four police agents are: environment, ownership, size, technology, and to assist the internal control system to adapt or cope with information technology requirements (Grand, 2003, p. 6).

\subsection{Problem Study}

This study attempts to answer the following questions:

1)- Does it help understand the work environment the banks internal control system to keep pace with information technology requirements?

2)- Is there a trace of owners to assist the internal control system to keep pace with information technology requirements?

3)- Is there an effect size of Jordanian commercial banks to help the internal control system to keep pace with information technology requirements?

\subsection{The Study Hypotheses}

From the problem of the study the study hypotheses can be formulated following.

1)- Does not help to understand the business environment of banks internal control system to keep pace with information technology requirements.

2)- There is no impact to owners to assist the internal control system to keep pace with information technology requirements.

3)- There is no impact to the size of the Jordanian commercial banks to help the internal control system to keep pace with information technology requirements.

\subsection{Significance of the Study}

Sharp differences between the economic and financial returns highlight the importance of conditional factors. These include the communities' technical and managerial skills, access to finance, legal resources and market information, and the communities' capacity for vertical integration. The cases highlight the limitations of the current regulatory and policy framework as a determining influence on the exploitation of community forests and conclude there is a pressing need for institutional and organizational reforms within the governmental and support apparatus to increase the profitability and equity of community forestry.

To sharpen competitive nowadays, led to a shift in the methods of management of organizations and the nature of their working systems, as a result of competition in the industrial era to compete in the age of information and technology to the growing needs of the Department, and the conditional factors may affect the design of control systems of the company, and the contents of the conditional supervision, there is no consistent regulatory regime unchanged but must change as the company changes and updates information systems, this The information technology, therefore significance in highlighting the systems used by the accounting and at various stages of development which enabled them to provide information on good decision-making, leading to optimal utilization of economic resources generally, and use programming targets particular decision-making.

\subsection{The Objectives of the Study}

1)- highlight the concept of conditional and control areas of evolution and their uses:

2)-Identify the linking of police supervision of the internal control system and identify the impact of these link in promoting the concept of banking supervision.

3)- Learn about the impact of the computerized work environment on the development of police oversight and its impact on the internal control system.

4)- Proposals that support decision-making in a changing technological developments and their impact on internal control methods in information technology tools through the use of mathematical and statistical methods.

\subsection{Methodology and Method Study}

In order to achieve the objectives of the study and test her homework done on the following.

1)-Inductive approach: by reference to the reference books related to the subject of police oversight and internal 
control system, and previous relevant studies in the concept of police oversight and internal control system through the implications of ICT tools from the study variables.

2)- Deductive approach: through the questionnaire user-friendly design and characteristics of the study include the study variables and assumptions.

\subsection{Society and the Study Sample}

The study population consists of IT auditors at commercial banks in Jordan, where it is based and telephone communications on the Web sites of commercial banks in Jordan showed that the number of it. Auditors in banks 92 information technology auditors was distributed questionnaires to the community and has been collecting all valid identification and 64 for statistical analysis.

\subsection{Previous Studies}

1)- Study of Al-Hosban 2013 "the role of the external auditor on the review of accounting software in the electronic work environment at commercial banks in Jordan.

The study had clarified the definition of the role and nature of the work of the external auditor in the technological development in the environment of e-business accounting and the great development of the computerized accounting information systems. therefore, this study aimed to identify the benefits and costs of implementing accounting information systems in the short term and the long term it also clarified the nature of the work of the external auditor on the audit risks of handling as identified and how to handle it so that any technological development must be accompanied by certain risks as to the definition of the report of the auditor Internal and external auditors ' dependence in the electronic work environment.

The study on the identification of two parts, the first consisting of variables, demography and the second part on hypotheses and study terms, been using the alpha test of the credibility of the study, was $76 \%$ and regression is used to test hypotheses. One of the most important results of the study: the external auditor to determine the value of the data in order of priority for the company, the need for control by external auditors on the accounting data transmission networks between authorized persons and making clear in the report that the accountant can face and how to deal with them. The main recommendations of the study: the auditor to report first to the risk control for the level of assurance to all of account balances and to take into account the auditor the audit risks and try to anticipate or mitigate them with a comparison of the costs and benefits of using a Computerized information systems or maintain the old system or development it.

2)- Study of Hussein, 2013 "information technology and its impact on the quality of the accounting and regulatory performance in financial institutions of Yemen".

This study aimed to describe the impact of information technology on accounting and regulatory performance, and the impact on health of accounting systems and the credibility of the financial statements. One of the main results of this study that the application of information technology tools helps strengthen the competitiveness and development of accounting information system. One of the most important recommendations, giving special attention to financial institutions in areas deficient in accounting and regulatory performance and work to raise the level of performance to keep pace with developments in the accounting information technology tools.

3)- study of Ingram "Impacts of community forests on livelihoods in Cameroon: lessons from two case studies".

Community forestry is considered a tool for decentralization and devolution and as efficient strategy to achieve the multiple goals of sustainable resource management and poverty alleviation. However, evidence worldwide has shown mixed results. A financial, economic and environmental cost-benefit analysis of two community forests in Cameroon revealed that community forests are economically and environmentally profitable, and benefit communities more, compared to a baseline situation. Sharp differences between the economic and financial returns highlight the importance of conditional factors.

4)- Study of Salem 2009 "adapted internal control systems with the use of information technology and its impact on the reliability of the financial statements".

This study aimed to identify the importance of internal control and the need to adapt the use of ICT tools and their impact on the reliability of the financial statements in the Libyan-owned commercial banks, and is used to identify the study. study the following results: a high level of adaptation of the internal control systems in dealing with information technology environment, a quality suitable for a credibility in the financial statements as a result of an internal control system. The main recommendations of the study: the development of internal control systems and the use of information technology tools for enhancing quality of accounting information, and the development of regulations and instructions in Libya so as to adapt to the demands of information technology 
tools in the internal control system.

5)- Study of Baccasam 2003 "Continuous Monitoring of Enterprise Application Risk".

This study aimed to show the importance of supervision and the need to change the way by changes in business and economic conditions, and to identify the types of risks that may be encountered in the process of supervision and the most important types of information technology risk and risks affecting the company's infrastructure, the other type is the operational risks related to the performance of software and the efficiency and effectiveness of the operational process and information security.

It also aimed to show the role of internal control and internal audit in the process of overseeing the activities of the company so it can change the way of supervision by technological developments, taking into account the risks and how to deal with it, and finally to show some characteristics of supervision company mainly: information to be integrated with automated policy management, select the speed required by the Auditors and managers to identify problems of automated information. One of the most important findings of this study: The exception management approach best management style to oversee company operations complex, the use of software gives Auditors an overview of company performance and identify work hazard, and supervision is even more important with the increasing speed of development of the company and its operations and become more integrated.

1.7.1 The Current Study Differed from Previous Studies.

1)- The study identified specific factors to conditional adjustment of internal control systems.

2)- This study has linked it with the internal control system of conditional factors to come up with a compromise proposal to build an internal control system which takes into account the developments of technology with related parties.

3)- Study of the effect of using the computerized work on the development of internal control systems and the ability to modify or change such systems as in the accounting working environment.

\section{The Theoretical Framework of the Study}

Information technology can be defined as follows: it is based on the use of computers and other advanced methods in processing the data obtained and the speed in processing, storage and retrieval and transfer them to reliable information and dependable in making timely decisions (Al-Hosban, 2009, p. 56).

Information technology can be defined as the audit is based on the use of computers and computer networks to provide information required for audit and use it as a tool, and help in understanding the goal of automated accounting systems work, add to the understanding of the operating environment of modern technology, and the need to keep up with recent discoveries to capability to deal with them (Grand, 2003, p. 3).

Impact of information technology in public oversight of the existing computer environment and processing, and affect the efficiency of the Organization in General, the following: provision of security and system development, maintenance and change control and achieve control of computer operations that contain databases and networks planning (Mair, 2002, p 12).

Situational theory relies on the logic of the President is not having one good way for organizations to follow all the time and when you apply the accounting there is no adequate accounting systems may be applied equally to all organizations in all circumstances, and instead the characteristics of accounting system depends on the specific circumstances and the decision should study and situation analysis (environmental) impact on the effectiveness of the Organization, and this depends on the decision maker to environmental factors (David, 2001, p. 28).

The organization is open to interaction with the environment, and that there are many environmental factors that affect the functioning of the organization, the organization must adapt to their environment in order to sustain and survive and grow, as the organization must adapt to their environment in order to increase their effectiveness. Environment defined as "all the elements outside the Organization and its possible impact on it and include: competitors, resources, technology, economic conditions, and is also surrounded by the Organization and consists of a combination of factors." The relationship between the environment and the mutual organization, there must be a capacity to adapt to the mobile environment, static forms and complex and usually exceed the conditions of uncertainty, and the environment must be seen as a source of information and storage resources, and directors found the environment by understanding her (Odeh, 1999, p. 66).

In order to get auditors come from effective use of computers as a tool for auditing and the use of automated proofing systems and understanding of the environment's regulations and those of the company, especially in the 
information technology environment, identify environmental factors affecting business and information extraction from the environment and that the company take decisions in good time, especially if the environment is rapidly changing, as well as the ability to identify emerging issues and ICT issues (Grand, 2002, p 9).

When the auditor determines the conditions of uncertainty in the information technology environment conditions, those conditions should be measurable as a percentage of the circumstances confirm that this internal control system to identify strengths, weaknesses and attempt to mitigate the weaknesses and strengths of the company, so that your IT environment is complex (Ozier, 1999, p. 14).

The process of understanding the company's operating environment requires a long experience in dealing with environmental factors also need to be trained in information technology risk affecting the working environment of the company, the auditor must also exercise training and education programmers on information security risks and their impacts on the environment and especially under regulations issued by the Department or the internal control system (Ozier B, 2001, p. 8).

The electronic work environment whose auditors review the level of integration of internal control with the information technology environment, to provide management information technology systems stability and control of environmental factors in addition to providing the Administration how to improve the control systems information technology environment (Oliphant, 2004, p. 25).

The most important activities related to the it environment and that must be the focus of the Auditors: information processing and control physical oversight of sensitive assets and the separation of powers, and control the correct recording of transactions and events in a timely manner and provide information (The Palestinian Association of accountants and Auditors, 2002, p. 12).

Can drive more than you expect for old computers, as they try to keep them as long as possible, and consider the information technology organizations to reduce costs, these services need to have the tools of modern technology so that they can achieve that goal, which means the need for additional costs for many variables that you will get from it. Here comes the role of internal audit in the company must evaluate the risks of the technology related to the possession of old computers and suitability for the accounting software of the company and assessment of the additional costs for the company (Mccllum, 2003, p. 29).

Most companies also started to assess the risks of owning a certified software necessary to run the accounting software, as well as other costs associated with accounting software, and the extent of its presence in the company, and the specification of computers needed to run those programs. And that means the cost associated with automated accounting software and tools to run, such as a certificate of purchase program Windows or other programs like Excel or access, so comes the role of internal audit and the internal control system in determining the extent of a company and auditing tools and identify specific costs and other related costs, in addition to assessing the need for such programmers and other tools as the it environment changes that affect business and company activities. One of the most important reasons for using accounting software companies is to find and identify a position (Silton, 2003, p. 4).

Because of the rapid change in information technology, it is necessary to own the development of control procedures in order to be effective, changes in technology and its applications and the transition to electronic commerce and the expansion of applications of communication networks, will change the specific regulatory activities and can be applied and how to apply them. As computers developed put additional responsibilities for data processing to the end user, it is necessary to determine the appropriate control procedures and application (Jagdish, 2000, p. 13).

The agent property in corporations is a policeman to adopt information technology as the use of technology in the home would be costly for the company and thus affect the profits of the company as well as the rapidly changing regulations under the information technology environment that increases the risk to the assets and property of the company and the shareholders' strong influence on board as General Authority the property affects the management philosophy and trends, as well as to the organizational structure of the company, and the property affect corporate performance by influencing their objectives which are based primarily on profit, and profit with high demands to engage in risk equivalent, where bureaucratic level drops, and the element property is of great influence on changing the style and type of centralized or decentralized also affects the focus or intensity of external oversight (Odeh, 1999, p. 62).

The Board of Directors in companies subject to supervision, it is not the end, because of the recommendations and the powers of the Governing Council shall enact from shareholders and the owners are established by the company, as they put their money in for profit, and on the Board of Directors, external oversight by the auditor 
appointed by the shareholders (Al- Khammash, 1997, p. 34). The auditor's responsibility to bring the views and expectations between the Board and the shareholders (expectations gap), and the auditor to report to shareholders on the credibility of the financial statements and accounting principles agreed at the end of the fiscal year, and should have a good knowledge of developments in the company's activities (Dahmash, 1997, p. 3).

The culture and learn about the threats to information and communication technology environment in the company could prevent repeated errors which may affect the continuation of the company, the employees in these companies should be able to exchange experiences among themselves, on the other hand, experts in information security, they must identify and manage risks that threaten the adequacy, reliability and integrity of the underlying assets of the company (Ozier, 2003, p. 7).

With the increasing volume and complexity of its projects became the owners of the project and its task as a result of the gap between the Administration and implementing processes, it became incumbent on managers to rely on data and statistics and summaries, and began using the internal control management to help it to carry out its functions and to ensure compliance with plans and policies and ensure protection of the assets of the business, and the use of computers has led to a multiplicity of automated accounting software in the market and a variety of electronic books is commensurate with the nature and size of the business, leading to easy handling With these books very quickly in different stages at registration, amendment or cancellation of the data (Oliphant, 2002).

The change in the world of trade and business environment in the present era, and the increased volume of operations, and complexity, globalization, and information technology, the computer revolution, and the volume of financial markets and the world, these events were the auditor has the ability of persuasion, motivation and adaptation to emerging situations such as information technology and other developments in the world of information systems and email (Grand, 1998, p. 5).

Identifies the volume as "the work of the Organization and its responsibilities as it is a measure of the Organization's operations, and is the set of elements reflecting the core components and the main activities of the Organization". Size is one of the key variables affecting the expansion of business activities, as reflected by four elements: the number of employees, and the volume of work, and the size of the assets, organizational structure and increase the size of the organization leads to complex accounting control systems, and large enterprises using advanced control systems increase the official proceedings, and increase the size to achieve significant benefits by expanding the area of control (Odeh, 1999, p. 71).

Large organizations use information technology in their departments and branches to control information, but information technology budgets are an obstacle to achieving this goal, so preferably those balancers proportion of revenue rather than a specific amount, and Auditors should focus on expanding the information and try to adjust its deployment in large organizations because it will have a wide range of information about internal activities in order to be a certified public accountant who specializes in information technology based information classification according to their importance to the company. In General, large organizations have the capacity to adopt information technology more than small organizations, because small organizations cannot invest large sums or carry significant risks arising from information technology (IIA, 2003, p. 2).

With the magnitude of the project and its complexity, it became impossible for project owners and management to scrutiny as a result of the gap between the Administration and implementing processes, it became incumbent on managers to rely on data and statistics and summaries, and began using the internal control management to help it to carry out its functions and to ensure compliance with plans and policies, and from here emerged the need for internal audit to ensure the validity of financial statements and internal control systems and compliance (Abd Al-Munem, 2002, p. 36).

The size is an important element affecting the design of control systems, the importance of several reasons including: the technology source for productivity and restructuring activities and their impact on the behavior of workers and restructuring of operations. And technology is a representation of the extent to which production processes are governed by the results that can be controlled, as there is a relationship between technology and the structure of the Organization so that the greater the technological complexity in the Organization the organizational structure tends to be organically growing with power levels, the main factor in technology is the degree of interdependence between sub-units and determined through coordination between individuals and groups within the Organization.

\section{Statistical Analysis}

After the conditional factors and their impact on the configuration of the internal control system in commercial banks from the point of view of the internal auditors, this chapter will examine the results of the field study, 
specifically the following topics will be discussed: characteristics of the study sample, the members discuss the statistical results from the arithmetic mean and discussion to test hypotheses and test credibility alpha.

\subsection{Validity and Reliability}

Alpha has been using the test of credibility for the degree of internal coherence in the study sample members and answers that range from 0 to 1 , and the minimum based on the findings and recommendations of the study is $60 \%$, and the alpha value as the study sample members answers is $73 \%$ which is higher than the minimum, which means there is sincerity and constancy in the study sample members answers to paragraphs of resolution.

\subsection{Characteristics of the Study Sample Members}

First: personal information

This section contains three variables are age, education, years of experience and job title, and were as follows:

Table 1. Sample according to age

\begin{tabular}{lll}
\hline Statement & Frequencies & Percentage \\
\hline 20- less than 25 years & 13 & $\% 21$ \\
25- less than 30 years & 18 & $\% 28$ \\
30- less than 40 years & 23 & $\% 36$ \\
40 years and more & 10 & $\% 15$ \\
Total & 64 & $\% 100$ \\
\hline
\end{tabular}

Notes from table 1 that the sample is suitable for setting within the age categories as noted that $30-40$ years is one of the highest categories, followed by 25-30 years and 40 years or more as a percentage, this may indicate a years experience among members of the study sample, either theoretical or practical because there is a relationship between age and years of experience, the greater the age, the more years of experience, which gives an indication of a good degree of credibility Study of high-resolution paragraphs so there is truth in the findings and recommendations emerging from this research.

Table 2. Sample according to education

\begin{tabular}{lll}
\hline Statement & Frequencies & Percentage \\
\hline BA & 38 & $\% 60$ \\
Master & 17 & $\% 26$ \\
PHD & 9 & $\% 14$ \\
Total & 64 & $\% 100$ \\
\hline
\end{tabular}

Notes from table 2 that most sample members who hold a Bachelor's degree from the various qualifications as noted that post graduate have good percentage is $40 \%$ and this is a positive indicator and gives credibility somewhat to rely on the findings and recommendations of the study and may give a positive indication of the sincerity of the answer and that the paragraphs of the resolution was clear.

Table 3. Sample according to years of experience

\begin{tabular}{lll}
\hline Statement & Frequencies & Percentage \\
\hline Less than 5 years & 19 & $30 \%$ \\
5- less than 10 years & 33 & $52 \%$ \\
10 years and more & 12 & $\% 18$ \\
Total & 64 & $\% 100$ \\
\hline
\end{tabular}

Note from table 3 that most members of the sample of the study experience class 5-less than 10 years and is a good time to judge the hypotheses of the study variables have a positive advantage in her sincerity and constancy study tool.

\subsection{The Taking of Decision}

I have been using a likert Pentagram Design resolution of five options for each paragraph of resolution for the 
purposes of statistical analysis was made using system encoding options so was given the following symbols 1)-. Very high degree given by the icon 5 .

2)- High score given by the code 4 .

3)- Medium is given by the symbol 3.

4)- Low given the symbol 2.

5)- Very low degree given by the symbol 1.

So the average premise for accepting or rejecting the hypothesis would be paragraph or the Middle premise 3, obtained by using a collection of icons and divided into a number of options which $(5+4+3+2+1) / 5$ is equal to 3 . So if the Center paragraph or hypothesis that is greater than or equal to the number 3 it means accepting a paragraph or more premise that setting the higher the degree of acceptance and confirmation of the study sample with that variable, and less central paragraph or hypothesis about the number 3 it means that the study sample tend to lack in practice, the greater the difference from the Center premise further confirm the appointed members in the absence of the effect of that variable in the Bank The study sample members.

3.4 Discussion of Statistical Results with Hypotheses of the Study Variables

Table 4. Views of the study sample, the variable information technology environment

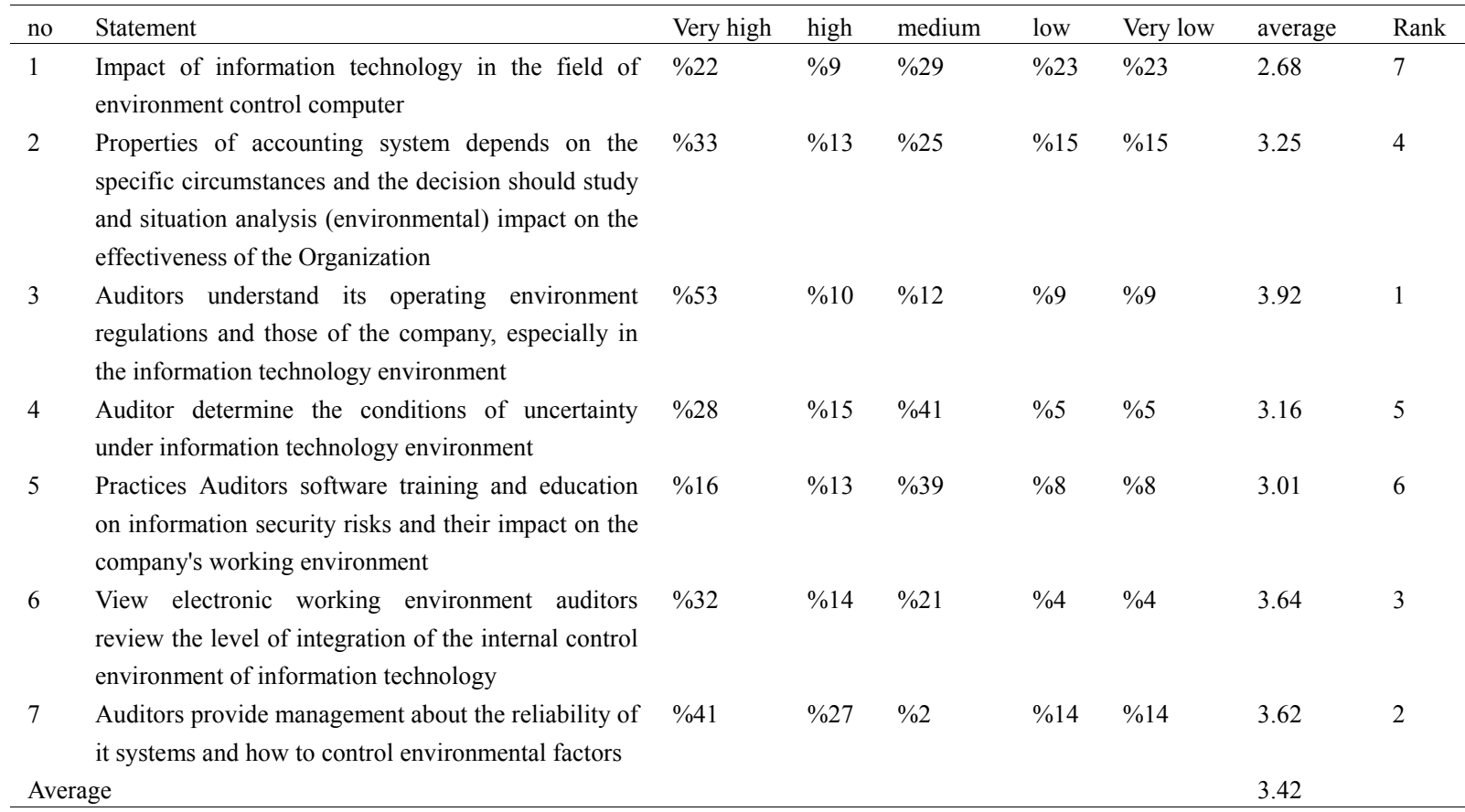

Notes from table 4 of the third paragraph is more degrees of acceptance among members of the study sample average 3.92, and this is evident from the percentages of the corresponding paragraphs in highly and very highly approved, and with the auditor's understanding of the operating environment systems within banks and regulations governing banking by monitoring bodies such as the Central Bank which oversees banking operations through electronic surveillance and information technology tools, also notes that the seventh paragraph is a Acceptance by the members of the study sample, and this is evident from the very high rates and high and this was reflected on the Mediterranean and this paragraph, represented by information technology auditor in commercial banks provide the Department about the stability of information technology systems and how to deal with internal and external environmental factors that might affect the goals of the strategy, the Bank also notes that the sixth paragraph of the Auditors ' objective is to review the information technology integration of internal controls with the ICT environment circumstances and situational updates governing banks either by customer orders or requirements of the State represented by the Central Bank to keep the funds of depositors that the Central Bank is the guarantor of citizens ' deposits in the Bank business. also notes that the average premise is 3.42 and is higher than the mean virtual 3 this shows that members of the sample supported the information 
technology environment impact on adjustment or design internal control systems as updates from either clients or State to ensure continue to market or achieve a competitive advantage.

Table 5. Reviews the sample variable ownership information technology tools

\begin{tabular}{|c|c|c|c|c|c|c|c|c|}
\hline no & Statement & Very high & high & medium & low & Very low & average & Rank \\
\hline 1 & $\begin{array}{l}\text { Possession of the tools of modern technology by } \\
\text { Auditors help reduce investment costs }\end{array}$ & $\% 47$ & $\% 18$ & $\% 23$ & $\% 7$ & $\% 5$ & 3.95 & 1 \\
\hline 2 & $\begin{array}{l}\text { The company's internal auditor's risk assessment } \\
\text { technology for owning computers old and suitability } \\
\text { for the accounting software of the company and } \\
\text { assessment of the additional costs for the company }\end{array}$ & $\% 15$ & $\% 34$ & $\% 15$ & $\% 10$ & $\% 26$ & 3.02 & 5 \\
\hline 3 & $\begin{array}{l}\text { The role of internal audit and the internal control } \\
\text { system in determining a company's information } \\
\text { technology tools, audit, and determine the costs for } \\
\text { those programs }\end{array}$ & $\% 14$ & $\% 19$ & $\% 9$ & $\% 31$ & $\% 27$ & 2.62 & 8 \\
\hline 4 & $\begin{array}{l}\text { The internal auditor shall ensure that proprietary } \\
\text { accounting software consistent with the policies and } \\
\text { strategies of the company }\end{array}$ & $\% 28$ & $\% 14$ & $\% 13$ & $\% 23$ & $\% 22$ & .3 .03 & 4 \\
\hline 5 & $\begin{array}{l}\text { Because of the rapid change in information } \\
\text { technology, it is necessary to own the development } \\
\text { of control procedures to be effective by Auditors }\end{array}$ & $\% 26$ & $\% 11$ & $\% 25$ & $\% 22$ & $\% 36$ & 3.29 & 3 \\
\hline 6 & $\begin{array}{l}\text { The agent property of information technology tools } \\
\text { in corporations is a policeman to embrace } \\
\text { information technology }\end{array}$ & $\% 4$ & $\% 36$ & $\% 12$ & $\% 27$ & $\% 21$ & 2.75 & 7 \\
\hline 7 & $\begin{array}{l}\text { The operator property of the ICT tools affect } \\
\text { management philosophy and trends, as well as to the } \\
\text { organizational structure of the company }\end{array}$ & $\% 9$ & $\% 28$ & $\% 10$ & $\% 42$ & $\% 11$ & 2.82 & 6 \\
\hline 8 & $\begin{array}{l}\text { The ownership of ICT tools is of great influence on } \\
\text { changing the style and type of centralized or } \\
\text { decentralized also affects the focus or intensity of } \\
\text { external oversight }\end{array}$ & $\% 51$ & $\% 8$ & $\% 14$ & $\% 20$ & $\% 7$ & 3.76 & 2 \\
\hline \multicolumn{2}{|c|}{ Average } & & & & & & 3.15 & \\
\hline
\end{tabular}

Notes from table 4 that the study sample tend to accept paragraph 9 the highest degree of acceptance, as is clear from a very high class and this reflected the average 4.29 and this paragraph is in possession of various information technology tools for accounting help Checker to perform duties thoroughly and this is reflected in the increased investment in information technology to reduce costs in the long-term perspective, notes that the second paragraph of the second impact on the degree of approval of the ownership Of information technology tools with a great effect on changing the style and type of centralized or decentralized also affects the focus or intensity of external control represented by the external auditor, as noted in the third paragraph have lower approval by members of the sample and of the role of internal audit and the internal control system In determining the extent of a company's information technology tools, audit, and determine the costs for those programs to apply cost-benefit policy and choose appropriate tools that assist in attaining the objectives of the audit of banks long term. Also notes that the average premise is 3.15 and is higher than the mean proposition 3 the study sample members agree that owning information technology tools such as the conditional operator has an impact.

Table 6. Reviews the study sample with variable size information technology tools

\begin{tabular}{|c|c|c|c|c|c|c|c|c|}
\hline no & Statement & Very high & high & medium & low & Very low & average & Rank \\
\hline 1 & $\begin{array}{l}\text { the internal control management to help it to carry } \\
\text { out its functions and to ensure compliance with plans } \\
\text { and policies and ensure protection of assets } \\
\text { established }\end{array}$ & $\% 16$ & $\% 4$ & $\% 21$ & $\% 36$ & $\% 3$ & 2.34 & 8 \\
\hline 2 & $\begin{array}{l}\text { Available to the auditor's persuasion, motivation, } \\
\text { capacity and adapt to new conditions, such as }\end{array}$ & $\% 14$ & $\% 27$ & $\% 12$ & $\% 43$ & $\% 4$ & 3.04 & 6 \\
\hline
\end{tabular}


information technology and other developments in the world of information systems and email due to the size of the company

3 To increase the size of the organization leads to complex accounting control systems, and large enterprises using advanced control systems increase the official procedures

4 To increase the size to achieve significant benefits by expanding the area of control

5 Increasing the size to achieve significant benefits by $\% 33$ expanding the area of control

6 Large organizations use information technology in their departments and branches to control information

7 Auditors focused on expanding the information and try to adjust its deployment in large organizations because it will have a wide range of information about internal activities

8 There is an accountant who specializes in information technology based information classification according to their importance to the company

9 The size of the critical elements that affect the design of the control systems, the importance of several reasons including: the technology source for productivity and restructuring activities and their impact on the behavior of workers and restructuring processes

\begin{tabular}{|c|c|c|c|c|c|c|}
\hline$\% 51$ & $\% 14$ & $\% 7$ & $\% 12$ & $\% 16$ & 3.72 & 1 \\
\hline$\% 4$ & $\% 63$ & $\% 16$ & $\% 8$ & $\% 9$ & 3.45 & 3 \\
\hline$\% 33$ & $\% 14$ & $\% 13$ & $\% 25$ & $\% 15$ & 3.25 & 5 \\
\hline$\% 28$ & $\% 14$ & $\% 13$ & $\% 23$ & $\% 22$ & .3 .03 & 7 \\
\hline$\% 32$ & $\% 29$ & $\% 14$ & $\% 21$ & $\% 4$ & 3.64 & 2 \\
\hline$\% 32$ & $\% 29$ & $\% 14$ & $\% 21$ & $\% 4$ & 3.64 & 2 \\
\hline$\% 31$ & $\% 23$ & $\% 12$ & $\% 25$ & $\% 9$ & 3.42 & 4 \\
\hline
\end{tabular}

Notes from the above table that the study sample confirms the acceptance of the third highest average of 3.72, and this is evident from the corresponding percentages of high and very high approval of the increased Bank size leads to complex accounting control systems, and large enterprises using advanced control systems increase the informal procedures which reflected the need to adopt internal control systems using ICT tools adapted to the latest technology, He also notes that paragraph 7 of the second degree is in the opinion of the members of the study sample and the concentration of Auditors to expand information and try to adjust its deployment in large organizations because it will have a wide range of information about internal activities which require a sophisticated means of security and protection and difficult handling accounting data between non-authorized persons or unauthorized access that achieves through ICT tools, also notes that the eighth ranking second in degree of acceptance, confirmation, according to members of the study sample, this paragraph is a specialized accountants using the tools of information technology to maintain the security and confidentiality of that information and connect to the right people at the right time. also notes that the first paragraph represent the lowest acceptance according to members of the study sample and this paragraph by using the internal control management to help it to carry out its functions and to ensure compliance with plans and policies and ensure protection of the assets of the company, which is one of the objectives of internal control can be maintained through human or electronic control or legal. also notes that the average premise is 3.3 , which is higher than the mean premise 3 and this shows that the study sample members acknowledge the impact of the size of the Bank as a policeman on the design of internal control systems in the information technology environment in commercial banks.

\subsection{Testing Hypotheses of the Study}

\subsubsection{First Hypothesis}

That "does not help to understand the business environment of banks internal control system to cope with the requirements of information technology".

I have been using the T-test for one sample One Way this t-test to the first hypothesis, the test results according 
to the following table:

Table 7. The first hypothesis test results

\begin{tabular}{lllll}
\hline The calculated T & Schedule T & T statistical significance & As a result the null hypothesis & Arithmetic mean \\
\hline 12.27 & 1.977 & 0 & Reject & 3.42 \\
\hline
\end{tabular}

Notes from table 7 so that the decision is to accept the hypothesis of nihilism (H0) if the value of the indexed value, and rejects the nihilistic hypothesis (H0) if the calculated value is greater than the value table. So we reject the hypothesis of nihilism and accept the alternative hypothesis that helps understand the work environment the banks internal control system to keep pace with information technology requirement

\subsubsection{Second Hypothesis}

And that "there is no trace of owners to assist the internal control system to cope with the requirements of information technology".

I have been using the T-test for one sample One Way Sample this t-test to the first hypothesis, the test results according to the following table:

Table 8. The second hypothesis test results

\begin{tabular}{lllll}
\hline The calculated T & Schedule T & T statistical significance & As a result the null hypothesis & Arithmetic mean \\
\hline 9.53 & 1.977 & 0 & Reject & 3.15 \\
\hline
\end{tabular}

Note from table 8 depending on the base type in the first hypothesis. So we reject the hypothesis of nihilism and accept the alternative hypothesis that there is a trace of owners to assist the internal control system to keep pace with information technology requirements

\subsubsection{Third Hypothesis}

And that there is no impact to the size of the Jordanian commercial banks to help the internal control system to cope with the requirements of information technology.

I have been using the T-test for one sample One Way Sample this t-test to the first hypothesis, the test results according to the following table:

Table 8. The third hypothesis test results

\begin{tabular}{lllll}
\hline The calculated T & Schedule T & T statistical significance & As a result the null hypothesis & Arithmetic mean \\
\hline 3.30 & 1.977 & 0 & Reject & 7.94 \\
\hline
\end{tabular}

Notes from table 8 depending on the base type in the first hypothesis. So we reject the hypothesis of nihilism and accept the alternative hypothesis that there is a trace of the size of the Jordanian commercial banks to help the internal control system to keep pace with information technology requirements.

\section{Findings and Recommendations}

\subsection{Findings}

1)-Auditors understand its operating environment regulations and those of the company, especially in the information technology environment and this helps the internal auditor on the effectiveness and strength of the internal control system through the use of information technology tools.

2)- An Auditors provide management about the reliability of it systems and how to control environmental factors both internal factors or external factors and internal oversight helps to identify opportunities and threats of the external environment and identify the strengths and weaknesses of the internal environment factors.

3)- The characteristics of the accounting system depends on the specific circumstances and the decision should study and situation analysis (environmental) impact on the effectiveness of the internal control system and the analysis of the environment in which the company operates to ensure continuity in the market through the use of information technology tools and the possibility of achieving competitive advantage for the Bank which is 
reflected on the profits of the banks in General.

4)- An Auditor shall determine the conditions of uncertainty in the information technology environment which reduces risks of modern technology and investment opportunities by internal oversight.

5)- Possession of the tools of modern technology by Checker help relieve the costs of investing in long-term term which reflected the banks ' strategies and objectives to achieve the desires of customers with the quality service you desire.

6)- Ownership of information technology tools has a great effect on changing the style and type of centralized or decentralized also affects the focus or intensity of external control that depends entirely on the regulatory environment for the internal control system and how to monitor and identify risks.

7)- The rapid change in information technology lead to the need for regulatory measures to be developed by the internal auditor and the external auditor to issue a decision on the adequacy of internal controls and systems in banks.

8)- Internal auditor shall ensure that State-owned banks accounting software in accordance with the policies and strategies that banks.

9)- To increase the size of the organization leads to complex accounting control systems, and large enterprises using advanced control systems increase the official procedures.

10)- Auditors should focus on expanding the information and try to adjust its deployment in large organizations because it will have a wide range of information about internal activities.

11)- The size of the critical elements that affect the design of the control systems, the importance of several reasons including: the technology source for productivity and restructuring activities and their impact on the behavior of workers and restructuring processes.

\subsection{Recommendations}

1)- Broad outline of the impact of information technology in the field of environment control computer.

2)- The auditor training and education programmers on information security risks and their impact on the company's working environment.

3)- Considering the factor of information technology tools in corporations as a policeman to embrace information technology.

4)- The operator property of the ICT tools affect management philosophy and trends, as well as to the organizational structure of the company in General and banks in particular.

5)- The role of internal audit and the internal control system in determining a company's information technology tools, audit, and determine the costs for those programs.

6)- use of internal control management to help it to carry out its functions and to ensure compliance with plans and policies and ensure protection of assets established.

7)- An Auditor's persuasion, motivation, capacity and adapt to new conditions, such as information technology and other developments in the world of information systems and email due to the size of the company.

8)- Conferences, seminars, known researcher conditional control factors on large business organizations particularly banks.

\section{References}

Abdel, M., \& Ahmed, H. (2000). Development concept and standards of professional performance of internal auditing under information technology environment. Journal of the Aiditor, 41-42.

Al-Hosban, A. (2013). The role of the external auditor on the review of accounting software in the electronic work environment in banking trade Jordan, Irbid llibohoth. Irbid National University, the acceptable publishing.

Al-Hosban, A. A. (2009). Oversight and auditing in accounting information systems environment (p. 56). Dar al-Hamid, Aman Jordan.

Al-Khammash, M. (1997). Corporate control law magazine (p. 30). Checker, Oman, Jordan.

Baccasam, V. P. (2003). Continuous Monitoring of Application Risk. IIA, 6.

Beauchamp, E. I. (2011). Impacts of community forests on livelihoods in Cameroon: lessons from two case 
studies. International Forestry Review, 3(4), 23-22. Using Audit Tools to Audit Software Asset, Audit Tolls.

Dahmash, N. (1997). The responsibilities of Auditors and Auditor expectations gap, magazine.

David, C. H. (2001). The Contingency Theory of Managerial Accounting. The Accounting Review.

Fisher, J. C. (1995). Based Research on Management control System Categorization By Level of Complexity. Journal of Accounting Research, 14.

Grand, C. (1998). Using CAATTs As Audit Tools. Audit Tools, 1.

Grand, C. (2003). Information Technology in Auditing theiia.

Hussain, N. (2009). Information technology and its impact on the quality of the accounting and regulatory performance. Master University of Sana'a, Yemen.

Jagdish, P. (2000). IT Audit Approach. Internal Control, 3.

Mair, W. (2002). ESAC Risk and Control Environment.

Mccollum, T. (2003). Technology Forum Addresses Desktop Management. Audit and Control, 6.

Odeh, A. G. (1999). Adapted control systems with the requirements of the privatization process. $\mathrm{PhD}$, University, Faculty of management and economics.

Oliphant, A. (2002). IT Auditors Certification. New IT Auditor, 15.

Oliphant, A. (2003). Computer Audit-A Positive Force for Internal Control.

Ozier, W. (1999). Framework for An Automated Risk Assessment Tools. Risk Management, 2.

Ozier, W. (2003). Information Security Risk Education and Awareness. Risk Management, 6.

Salem, M. N. (2011). Adapted internal control systems with the use of information technology and its impact on the reliability of the financial statements. Master thesis, Middle East Technical University, Amman, Jordan.

\section{Copyrights}

Copyright for this article is retained by the author(s), with first publication rights granted to the journal.

This is an open-access article distributed under the terms and conditions of the Creative Commons Attribution license (http://creativecommons.org/licenses/by/3.0/). 